\title{
Resilient Phenotype in Chronic Mild Stress Paradigm Is Associated with Altered Expression Levels of miR-18a-5p and Serotonin $5-\mathrm{HT}_{1 \mathrm{a}}$ Receptor in Dorsal Part of the Hippocampus
}

\author{
Dariusz Zurawek $^{1,2}$ D Piotr Gruca ${ }^{2}$ - Lucyna Antkiewicz-Michaluk ${ }^{3}$ - Marta Dziedzicka-Wasylewska ${ }^{2}$
}

Received: 2 January 2019 / Accepted: 24 April 2019 / Published online: 16 May 2019

(C) The Author(s) 2019

\begin{abstract}
Disturbed serotonergic signaling in the hippocampus observed in many individuals vulnerable to stress has been suggested as one of the primary factors contributing to the development of depression. However, little is known about the physiology of the brain in the resilient phenotype. Resilient subjects maintain a positive mood and psychological balance despite being under the stress influence. In our study, we generated stress-vulnerable and resilient rats by using a chronic mild stress (CMS) paradigm. Using different molecular approaches, we revealed that resilient animals exhibited a significantly decreased expression level of miR$18 \mathrm{a}-5 \mathrm{p}$ and, in the same time, an elevated level of 5-HT1AR in dorsal, but not ventral, part of the hippocampus. Described biochemical changes were not observed in animals behaviorally vulnerable to stress. Further, in vitro analysis showed that miR$18 \mathrm{a}-5 \mathrm{p}$ may be a negative epigenetic regulator of 5-HT1AR since the treatment of adult hippocampal neurons with miR-18a-5p mimic significantly lowered the expression level of mRNA encoding 5-HT1AR. Moreover, bioinformatic analysis of potential target genes expressed in the hippocampus and being regulated by miR-18a-5p showed that this microRNA may regulate biological processes, such as axonogenesis, which are important in the functioning of the hippocampus in both rats and humans. All these molecular features may contribute to serotonergic homeostatic balance at the level of serotonin turnover observed in hippocampi of resilient but not stress-vulnerable rats. Delineation of further molecular and biochemical markers underlying resilience to stress may contribute to the development of new antidepressant strategies which will restore resilient phenotype in depressed patients.
\end{abstract}

Keywords miR-18a-5p · Stress $\cdot$ Resilient $\cdot$ Depression $\cdot$ Serotonin 5-HT1a receptor $\cdot$ Hippocampus

\section{Introduction}

Stress, defined as the biological response of an organism to life-threatening events, is an integral component of life. In the

Electronic supplementary material The online version of this article (https://doi.org/10.1007/s12035-019-1622-2) contains supplementary material, which is available to authorized users.

Dariusz Zurawek dariusz.zurawek@uj.edu.pl

1 Faculty of Biochemistry, Biophysics and Biotechnology, Department of General Biochemistry, Jagiellonian University, Gronostajowa 7, 30-387 Krakow, Poland

2 Polish Academy of Sciences, Department of Pharmacology, Institute of Pharmacology, 12 Smetna Street, 31-343 Krakow, Poland

3 Polish Academy of Sciences, Department of Neurochemistry, Institute of Pharmacology, 12 Smetna Street, 31-343 Krakow, Poland brain, short-term stress evokes a series of molecular changes responsible for coping with an unsafe situation. However, when the stressful events persist over a prolonged period of time, they lead to an allostatic load in the brain and, in effect, the loss of its homeostatic balance, which may result in the development of stress-related mood disorders such as depression. Nevertheless, in a human population, we can observe individuals who are much less prone to the negative influence of stress than others. These subjects are defined as resilient. Although resilient behavior has been extensively investigated in the context of psychological studies since the 1970s [1, 2], research aimed at understanding the molecular bases of this behavioral phenotype is sparse. Therefore, the expansion of neurobiological and molecular studies to investigate the resilience phenomenon seems to be of prime importance and may result in the development of more efficient antidepressant strategies based on the restoration of the resilient phenotype among depressed subjects. 
Depressive disorders may be precipitated in an individual by an interaction between external stressful conditions and genetic and epigenetic predisposing factors [3-6]. In this context, much attention has been paid to microRNAs (miRNAs), which belong to a newly discovered class of pleiotropic, epigenetic regulators of a diverse set of biological processes [7]. Mature miRNAs are short (18-23 nucleotides), noncoding, single-stranded RNA transcripts that, among mammals, are highly evolutionarily conserved. miRNAs can affect gene expression patterns via degradation or inhibition of translation of their specific targets based on complementarity between the miRNA seed region and the targeted mRNA [8]. Recent evidence has shown impaired expression levels of different mature miRNAs in the brain of depressed suicides [9] as well as stressed animals $[10,11]$. It has been observed that a maladapted stress response is associated with changes in the expression of many different miRNAs in the hippocampus [12, 13] and frontal cortex [14]. Moreover, elevated serum levels of miR-132 and miR-182 negatively correlated with serum levels of brain-derived neurotrophic factor (BDNF) in depressed patients [15]. Twelve weeks of antidepressant treatment with escitalopram significantly altered the expression levels of 30 miRNAs in the blood of depressed patients [16]. Furthermore, chronic administration of fluoxetine increased the level of miR-16 in the serotonergic raphe nuclei in mice. This observation was associated with decreased levels of the serotonin transporter (SERT) in monoaminergic neurons and elevated levels of synaptic serotonin (5-HT) concentration [17]. This work shows that some of the brain miRNAs may mediate the therapeutic effects of antidepressant drug treatment.

Although recent advances have enhanced our understanding of the contribution of miRNAs in pathomechanisms of depression, little is known about their role in the regulation of specific downstream molecular targets and the development of a resilient phenotype. To further explore this issue, we examined the expression levels of a set of five different miRNAs (miR-18a-5p, miR-34a-5p, miR-135a-5p, miR-320$3 p$, and miR-674-5p) in the hippocampus (HIP) and nucleus accumbens septi (NAcc) of stress-susceptible and resilient animals. Both brain structures are important in the processing of emotions, and thus are of particular interest in studies on stress-related mood disorders [18, 19]. All miRNAs included in this work have been reported to be significantly involved in the regulation of central nervous system homeostasis and in the development of depressive disorders. For instance, increased expression of miR-18a-5p has been observed in the brain of the stress-vulnerable F344 rat strain [20] and in the basolateral amygdala of stressed adolescent rats [21]. Moreover, we previously observed reciprocal alterations in the expression levels of miR-18a-5p in the mesocortical circuit of resilient rats [22]. Using an animal model of depression, it has been shown that the antidepressant effect of chronic duloxetine treatment was associated with increased expression levels of miR-18a-5p in the hippocampus [23]. miR-34a may modulate individual stress-coping strategies by acting on corticotrophin-releasing factors in the dorsal raphe nuclei [24] and amygdala [25]. It has also been postulated that the serum level of miR-34a may correlate with the occurrence of depression [26]. Recent studies have shown that depressed human patients had decreased expression levels of miR-135a in the blood and brain [27] and that acute stress altered the expression level of miR-135a in the amygdala of stressed mice [28]. Another study reported that dysregulation in the blood levels of the miR-320 family may accompany depression [29]. Moreover, miR-320 is a potential regulator of neuronal regeneration and neurite outgrowth in the central nervous system [30]. Finally, a preclinical study has shown that traumatic stress can cause dysregulation in the expression of miR-674 in the amygdala as well as in the serum of stressed animals [31].

Serotonin5- $\mathrm{HT}_{1 \mathrm{~A}}$ receptors $\left(5-\mathrm{HT}_{1 \mathrm{~A}} \mathrm{Rs}\right)$ have been proposed as key mediators of serotonergic signaling in the hippocampus [32]. 5- $\mathrm{HT}_{1 \mathrm{~A}} \mathrm{R}$ belongs to a class of inhibitory $\mathrm{G}$ protein-coupled receptors and is widely expressed in the HIP, where it acts as an auto- or heteroreceptor and is located pre- and post-synaptically, respectively. Therefore, 5- $\mathrm{HT}_{1 \mathrm{~A}} \mathrm{Rs}$ may act in a dualistic manner by controlling serotonin tone and release as well as by modulating the cellular response to this monoamine in brain regions receiving serotonergic innervations. Chronic stress reduced the levels of $5-\mathrm{HT}_{1 \mathrm{~A}} \mathrm{Rs}$ in different brain areas (including the HIP) in depressed patients [32] and in an animal model of depression [33]. It has been postulated that hippocampal $5-\mathrm{HT}_{1 \mathrm{~A}} \mathrm{Rs}$ may be a molecular factor implicated in resilience to stress and response to antidepressant treatment [34, 35]. For instance, it has been observed that Flinders stress-resistant rats had a higher density of $5-\mathrm{HT}_{1 \mathrm{~A}} \mathrm{Rs}$ in the CA1 region of the hippocampus compared to stress-susceptible rats [36]. Another study has shown that resilience to stress and a good prognosis of an antidepressant response are associated with lower levels of $5-\mathrm{HT}_{1 \mathrm{~A}}$ autoreceptors [37] but not heteroreceptors.

Dysregulated function of both brain $5-\mathrm{HT}_{1 \mathrm{~A}} \mathrm{Rs}$ and miRNA transcripts are important in the pathogenesis of depression. Nevertheless, knowledge about their mutual regulatory interaction in the formation of stress-resilient and stresssusceptible phenotypes is vague. In this work, we attempted to delineate differences at the level of brain miRNA that might characterize anhedonic and resilient phenotypes. Moreover, we sought to determine whether alterations at the miRNA level may influence serotonergic homeostasis in the brains of animals expressing different behavioral responses to stress. Delineation of molecular factors associated with a resilient phenotype may not only result in a better understanding of the pathogenesis of stress-related mood disorders but may also open the way to the development of new antidepressant 
therapeutic strategies involving pharmacological manipulations at the level of microRNA.

\section{Experimental Procedures}

\section{Chronic Mild Stress Procedure}

Male Wistar Han rats (Charles River, Germany) were singly housed in plastic cages $(40 \times 25 \times 15 \mathrm{~cm})$ in standard housing conditions, i.e., $22 \pm 2{ }^{\circ} \mathrm{C}, 40 \%$ humidity, and a 12-h lightdark cycle, with water and food available ad libitum. At the age of 4 months, rats were adapted to the experimental conditions and trained to a drink palatable $1 \%$ sucrose solution for 6 weeks. After the training period, the animals were randomly divided into the control $(n=110)$ and stressed $(n=110)$ groups. Controls were housed undisturbed in a separate room. Stressed animals were subjected to two consecutive weeks of a mild stress regimen that consisted of two periods of food deprivation: $45^{\circ}$ cage tilt, stroboscopic illumination (150 flashes per min), and intermittent illumination (lights on and off every $2 \mathrm{~min}$ ); one period of soiled bedding, water deprivation, and paired housing. All mild stressors had a duration of 10-12 h. Sucrose consumption tests were performed at the end of each weekly stress regimen followed by $14 \mathrm{~h}$ of water deprivation. Sucrose intake was measured as a difference in bottle weight. Discrimination between anhedonic $(n=78)$ and resilient $(n=32)$ groups of animals was based on the retrospective analysis of changes in their sucrose solution intake under stressful conditions and related to the median split of the baseline sucrose intake of these rats. Moreover, anhedonic animals, in response to stressful conditions, decreased their sucrose intake by more than $20 \%$, while resilient subjects did not decrease their sucrose consumption levels compared to basal sucrose intake and non-stressed littermates. For further molecular analyses, we randomly chose 16 animals per group. The remaining rats were used for another experiment and were not included in this study. All behavioral experiments were approved by the II Local Bioethics Commission (Krakow, Poland) and were carried out in accordance with EU Directive 2010/63/EU for animal experiments.

\section{Serum and Brain Tissue Sample Collection}

Before the start of CMS, $0.5 \mathrm{ml}$ of tail-vein blood was collected from each rat. Then, $24 \mathrm{~h}$ after the last stressor and sucrose consumption test, all animals were sacrificed by decapitation. Trunk blood samples were collected, and brains were rapidly removed from the skull. Blood samples were kept at room temperature (RT) for $30 \mathrm{~min}$ to clot and then centrifuged at $4{ }^{\circ} \mathrm{C}$ at $\times 1500 \mathrm{~g}$ for $10 \mathrm{~min}$. Non-hemolyzed serum samples were frozen at $-80{ }^{\circ} \mathrm{C}$ and stored until use. For autoradiographic and in situ analyses, whole brains were frozen in a mixture of dry ice and heptane and then cut into $12-\mu \mathrm{m}$-thick coronal sections through the dorsal (bregma, -3.14 to $3.80 \mathrm{~mm}$ ) and ventral hippocampus (bregma, -4.80 to $5.60 \mathrm{~mm}$ ) using a Jung CM 300 cryostat microtome (Leica, Germany) and mounted on gelatin-coated slides and air-dried. For miRNA screening and RT-PCR, Western blot, and HPLC analyses, the HIP and NAcc were dissected from rat brains, HIP was divided into dorsal and ventral parts and all brain regions were immediately frozen on dry ice in Eppendorf tubes and stored at $-80^{\circ} \mathrm{C}$ until use.

\section{Serum Corticosterone ELISA}

Serum corticosterone (CORT) levels were measured using a commercially available rat corticosterone ELISA kit (Demeditec Diagnostics, Germany) strictly according to the manufacturer's protocol. The absorbance was determined at $450 \mathrm{~nm}$. Serum CORT concentrations were calculated from a calibration curve ranging from 15 to $2250 \mathrm{ng} / \mathrm{ml}$. To eliminate the effect of a circadian rhythm on rat serum corticosterone concentrations, tail-vein and trunk blood samples were collected from all animals between 10 a.m. and 1 p.m.

\section{Total RNA Including miRNA Purification}

Total RNA, including miRNA from tissue and cell samples, was extracted using the miRNeasy Micro Kit. The miRNeasy Serum/Plasma kit was used for the isolation of total RNA, including miRNA, from serum samples. All purification methods were performed automatically on a QIAcube robotic workstation according to the manufacturer's protocols (Qiagen, Germany). The purity and concentration of RNA samples were measured with a NanoDrop spectrophotometer (ThermoFisher, USA).

\section{Screening of miRNA Expression Changes in the HIP, NAcc, and Serum of Rats After 2 Weeks of CMS Using Custom-Made TaqMan Low-Density Cards (TLDA)}

Samples of pure total RNA, including miRNA from serum $(3 \mu \mathrm{l})$ and brain tissue $(1 \mu \mathrm{g})$, were reverse transcribed into cDNA using the TaqMan MicroRNA Reverse Transcription Kit and custom-made TaqMan MicroRNA Assay mixture (LifeTechnologies, USA) according to the procedure for multiplexing the RT step without preamplification while using TaqMan MicroRNA Assays. Next, $6 \mu$ l of cDNA was mixed with $44 \mu$ of pure water and $50 \mu \mathrm{l}$ of TaqMan Universal PCR MasterMix, no AmpErase UNG, and the whole mixture was loaded into the custom-made TaqMan low-density cards (TLDA) (Life Technologies, CA, USA). Real-time PCR was performed on the QuantStudio ${ }^{\mathrm{TM}} 12 \mathrm{~K}$ Flex system (Life Technologies, CA, USA) with default cycling conditions and automatic threshold values according to the 
manufacturer's protocol. Gene expression values were calculated using the delta-delta $C_{t}$ method and were normalized to U6 transcript for brain samples and geometric means of miR$106 \mathrm{~b}$ and let- $7 \mathrm{~g}$ for serum samples. Supplementary material 1 contains a list of all TaqMan MicroRNA Assays used in the experiment.

\section{Comparative Bioinformatic Analysis}

Bioinformatic analysis of the interaction between miR-18a-5p and rat $5-\mathrm{HT}_{1 \mathrm{~A}} \mathrm{R}$ mRNA was performed with the freely accessible online database miRWalk 2.0 [38]), which documented miR-18a-5p-binding sites within the coding sequence of 5$\mathrm{HT}_{1 \mathrm{~A}} \mathrm{R}$ mRNA and combined this information with two other miRNA-target prediction programs, i.e., TargetScan and miRanda. All prediction algorithms showed the miR-18a-5$\mathrm{HT}_{1 \mathrm{~A}} \mathrm{R}$ interaction. Gene ontology and KEGG pathway analyses of putative gene targets expressed in the hippocampal tissue and being regulated by miR-18a-5p were performed using GeneCodis3 software [39] based on calculations of a hypergeometric distribution followed by $p$ value corrections for multiple testing. A list of tissue-specific genes expressed in native, non-diseased hippocampal tissue was obtained from GTEx Portal (https://gtexportal.org) on 12/2018. Expression of a particular gene in the hippocampus was considered as detectable when TPM value in the database was more than 5 .

\section{Neuronal Cell Culture from Adult Rat Hippocampus and Immunocytochemistry}

Adult hippocampal neuron cell culture was performed according to a previously published protocol [40] with minor modifications. In brief, dissected hippocampi were cut in $0.5 \mathrm{~mm}$ thick slices and incubated at $30^{\circ} \mathrm{C}$ for $30 \mathrm{~min}$ in HibernateA medium without $\mathrm{CaCl}_{2}$ (BrainBits, USA) containing $2 \mathrm{mg} / \mathrm{ml}$ of papain (Sigma-Aldrich, Germany). Digested slices were triturated and fractionated on an Optiprep 1.320 gradient (Sigma-Aldrich, Germany). The neuronal fraction was collected, rinsed with HibernateA/B27 and centrifuged for $1 \mathrm{~min}$ at $\times 200 \mathrm{~g}$. The cell pellet was resuspended in NeurobasalA/B27 medium containing $1 \mu \mathrm{g} / \mathrm{ml}$ gentamycin, $0.5 \mathrm{mM}$ Glutamax, and $10 \mathrm{ng} / \mathrm{ml}$ fibroblast growth factor (ThermoFisher, USA). Neurons were seeded (250,000 cells/ slide) on poly-D-lysine-coated glass coverslips (Merck, Germany) and maintained for 10 days at $37{ }^{\circ} \mathrm{C}$ under a $5 \%$ $\mathrm{CO}_{2}$ humid atmosphere. For immunocytochemistry, cell cultures were rinsed with PBS, fixed in $4 \%$ paraformaldehyde for $30 \mathrm{~min}$ at $37^{\circ} \mathrm{C}$ and pre-blocked for $1 \mathrm{~h}$ at RT in PBS containing $5 \%$ bovine serum albumin and $0.1 \%$ Tween 20 (SigmaAldrich, Germany) followed by overnight incubation at $4{ }^{\circ} \mathrm{C}$ with the same blocking solution enriched with anti-MAP2 (neuronal marker; M9942) and anti-GFAP (astroglial marker; EP6724) primary antibodies at a final dilution of 1:500. The next day, the cells were rinsed $3 \times 5$ min with PBS and incubated for $1 \mathrm{~h}$ at RT with donkey-Cy3 (AP182C) and goatAlexaFluor 488 (ab150117) secondary antibodies diluted 1:500 in blocking solution. Then, the cells were washed $3 \times$ for 5 min in PBS and mounted in SlowFade ${ }^{\mathrm{TM}}$ Gold Antifade Mountant with DAPI (ThermoFisher, USA). Fluorescently labeled cells were examined using an AxioImager 2 fluorescence microscope equipped with Zen 2 Pro software (Carl Zeiss MicroImaging GmbH, Germany).

\section{Transfection of Hippocampal Neurons with miR-18a-5p Mimic}

Neuronal cells were transfected with either $20 \mathrm{nM}$ miR-18a$5 \mathrm{p}$ mimic or Silencer ${ }^{\circledR}$ Select negative control (ThermoFisher, USA) using the N-TER ${ }^{\text {TM }}$ Nanoparticle siRNA Transfection System (Sigma-Aldrich, Germany) according to the manufacturer's protocol. Forty-eight hours post-transfection, neuronal cells were washed in ice-cold PBS and used for further molecular experiments. Silencer® Select negative control had no significant sequence similarity to rat genes and was used to verify the specificity of the miR-18a-5- $\mathrm{HT}_{1 \mathrm{~A}} \mathrm{R}$ mRNA interaction.

\section{RT-qPCR Analysis}

A total of 700 ng of total RNA from brain and cell samples was reverse transcribed into cDNA using a High-Capacity cDNA Reverse Transcription Kit (ThermoFisher, USA). Next, $0.5 \mu \mathrm{l}$ of cDNA was mixed with $8.5 \mu \mathrm{l}$ of water, $10 \mu \mathrm{l}$ of TaqMan ${ }^{\mathrm{TM}}$ Gene Expression Master Mix and $1 \mu$ l of genespecific TaqMan ${ }^{\mathrm{TM}}$ Gene Expression Assay (ThermoFisher, USA). The RT-PCR reaction was run on a CFX96 Touch ${ }^{\mathrm{TM}}$ Real-Time PCR Detection System (Bio-Rad, Germany) using default thermal cycling conditions. Raw $C_{t}$ values were analyzed and normalized to $\beta$-actin control using the delta-delta $C_{t}$ method. Supplementary material 1 contains a list of all TaqMan Gene Expression Assays used in the experiment.

\section{5-HT ${ }_{1 A} \mathrm{R}$ mRNA Expression: In situ Hybridization}

Brain sections were fixed in ice-cold $4 \%$ formaldehyde for $10 \mathrm{~min}$, washed in phosphate-buffered saline (PBS), incubated for $10 \mathrm{~min}$ in an ice-cold $0.1 \mathrm{M}$ triethanolamine $-0.25 \%$ acetic anhydride mixture and dehydrated in a graded series of alcohol followed by two 10-min incubations in chloroform. A mixture of three oligonucleotides complementary to rat 5$\mathrm{HT}_{1 \mathrm{~A}} \mathrm{R}$ mRNA was used as follows:

- 5'ATGAGCAACAGCGGGATATAGAAAGCGCCGAA AGTGGA3'

- 5'TGGTAGCTGAAGGTCACGTCGGAGATGCTAGT AACGTTGCCGCC3' 


\section{- 5'TGGAGTAGCCTAGCCAGTTAATTATGGCACCC AACAACGCAGG3'}

Oligonucleotides were designed using BLAST software and are specifically complementary to three different 5$\mathrm{HT}_{1 \mathrm{~A}} \mathrm{R}$ mRNA sites to increase the detection sensitivity of the in situ technique. Terminal transferase (Fermentas, Lithuania) was used to radiolabel oligoprobes at the $3^{\prime}$ ends with $\left[{ }^{35} \mathrm{~S}\right] \mathrm{dADP}$ (Hartmann Analytic, Germany). Radiolabeled oligonucleotides were suspended at a concentration of $1 \times 10^{6} \mathrm{dpm}$ per $50 \mu \mathrm{l}$ of hybridization buffer. Brain slices with applied hybridization buffer containing radiolabeled oligonucleotides were incubated for $18 \mathrm{~h}$ at $37{ }^{\circ} \mathrm{C}$. After hybridization, tissue slices were washed four times in $1 \times \mathrm{SSC}$ solution for $15 \mathrm{~min}$ each at $42{ }^{\circ} \mathrm{C}$, briefly immersed in distilled water and absolute ethanol, air-dried, placed into X-ray cassettes and exposed to film plates (Kodak, Japan) for 30 days at $-20{ }^{\circ} \mathrm{C}$. The developed radiograms were quantified using ImageGauge software (Fujifilm, Japan).

\section{Western Blot Analysis}

Hippocampi were homogenized in buffer containing $7 \mathrm{M}$ urea, $2 \mathrm{M}$ thiourea, $40 \mathrm{mM}$ Tris, 4\% CHAPS, $65 \mathrm{mM}$ DTT, and protease inhibitor cocktail (Merck, Germany) and then centrifuged at $10000 \mathrm{~g}$ for $10 \mathrm{~min}$ at $4{ }^{\circ} \mathrm{C}$. Supernatants were collected. Total protein concentrations were measured using Bradford reagent (Sigma-Aldrich, Germany). Twenty-five micrograms of total protein per sample was mixed with $2.5 \mu \mathrm{l}$ of Bolt@LDS Sample Buffer denatured for $10 \mathrm{~min}$ at $70{ }^{\circ} \mathrm{C}$ and loaded into precast Bolt ${ }^{\mathrm{TM}} 4-12 \%$ Bis-Tris Plus Gel (ThermoFisher, USA). Electrophoresis was run in Bolt ${ }^{\circledR}$ MES buffer (ThermoFisher, USA) for $45 \mathrm{~min}$ under a constant voltage of $165 \mathrm{~V}$. Separated proteins were transferred to a cellulose membrane using an iBlot $^{\mathrm{TM}}$ Western Blotting System (ThermoFisher, USA) according to the manufacturer's protocol. Protein bands of interest were visualized using an iBind ${ }^{\mathrm{TM}}$ Western Kit (ThermoFisher, USA) according to the manufacturer's protocol and using antibody dilutions as follows: anti$5-\mathrm{HT}_{1 \mathrm{~A}} \mathrm{R}$ (sc-1459), 1:200; anti- $\beta$-actin (A5441), 1:1000; anti-glucocorticoid receptor (3660s), 1:200; anti-mineralocorticoid receptor (ab64457), 1:200 primary antibodies and IgG-HRP (sc-2350), 1:100; (A9044), 1:4000; and (ab6721), 1:1000 secondary antibodies. The signals were developed using Clarity ${ }^{\mathrm{TM}}$ Western ECL Blotting Substrate (Bio-Rad, USA) and visualized with the use of Luminescent Image Analyzer Fuji-Las 4000 (Fuji, Japan). Immunoreactive bands were quantified using ImageJ software.

\section{$\left[{ }^{3} \mathrm{H}\right] 8-\mathrm{OH}-\mathrm{DPAT}$ Binding to $5-\mathrm{HT}_{1 \mathrm{~A}} \mathrm{R}$}

Brain slices were hydrated in $50 \mathrm{mM}$ Tris- $\mathrm{HCl}$ buffer for $30 \mathrm{~min}$ at RT and then incubated for $1 \mathrm{~h}$ at RT in $50 \mathrm{mM}$ Tris- $\mathrm{HCl}$ containing $4 \mathrm{mM} \mathrm{CaCl}, 0.1 \%$ ascorbic acid and $2 \mathrm{nM}\left[{ }^{3} \mathrm{H}\right] 8-\mathrm{OH}-\mathrm{DPAT}$ (Perkin Elmer, USA). To determine nonspecific radioligand binding, parallel brain slices were incubated for $1 \mathrm{~h}$ at RT in the same buffer enriched with $10 \mu \mathrm{M}$ serotonin (Sigma-Aldrich, Germany). The $\left[{ }^{3} \mathrm{H}\right] 8-\mathrm{OH}-\mathrm{DPAT}$ concentration corresponded to the $K_{d}$ value [41]. Radioligand incubation was terminated by three washes in ice-cold $50 \mathrm{mM}$ Tris- $\mathrm{HCl}$ buffer for 5 min. Tissue slices were then briefly immersed in distilled water, air-dried, and exposed to Fuji Imaging Plates (Fujifilm, Japan) with autoradiographic microscales (GE Healthcare, Germany) for 7 days. Developed autoradiograms were quantified using ImageGauge software (Fujifilm, Japan).

\section{High-Performance Liquid Chromatography (HPLC) of 5-HT and 5-Hydroxyindolacetic Acid (5-HIAA)}

Levels of 5-HT and its metabolite 5-HIAA were measured according to a previously described method [42]. In brief, weighed hippocampi were homogenized in icecold $0.1 \mathrm{M}$ trichloroacetic acid with $0.05 \mathrm{mM}$ ascorbic acid and centrifuged at $10000 \mathrm{~g}$ for $5 \mathrm{~min}$. Supernatants were filtered through RC58 cellulose membranes (Bioanalytical Systems, USA). 5-HT and 5-HIAA levels were measured on a Hypersil BDS-C18 $(4 \times 100 \mathrm{~mm}$, $3 \mu \mathrm{m})$ column with the use of an HP 1050 chromatograph (Hewlett-Packard, USA). For the mobile phase, $0.05 \mathrm{M}$ citrate-phosphate buffer $(\mathrm{pH}$ 3.5) enriched with $1 \mathrm{mM}$ sodium octyl sulfonate, $3.5 \%$ ethanol, and $0.1 \mathrm{mM}$ EDTA was used at a flow rate of $1 \mathrm{ml} / \mathrm{min}$. Peak areas for 5-HT and 5-HIAA were quantified with the use of ChemStation software and were compared to the standards.

\section{Statistical Analysis}

The results from the CMS procedure and body weight gain were analyzed with the use of repeated measures ANOVA followed by Bonferroni's post hoc test for multiple comparisons. All biochemical and molecular results were analyzed with the use of one-way ANOVA followed by Tukey's post hoc test. Statistical analysis of the data was performed using GraphPad Prism7 software (GraphPad Software Inc., USA). GO biological processes and KEGG pathways significantly enriched with targeted genes were calculated by hypergeometric distribution and $p$ values were corrected for multiple testing. 


\section{Results}

\section{The Effect of 2 Weeks of CMS on Sucrose Consumption, Serum CORT Concentration, and CORT Receptor Levels in Rat HIP}

Before the start of the CMS procedure, all tested animals showed the same levels of consumption of a palatable $1 \%$ sucrose solution (Fig. 1a). Repeated measures ANOVA showed a significant effect of stress $\left(F_{2,135}=34,1\right.$; $p<0.0001 ; n=16)$, time $\left(F_{2,135}=8579 ; p<0.0003 ; n=16\right)$, and an interaction of stress $\times$ time $\left(F_{2,135}=7.49 ; p<0.001\right.$; $n=16$ ) on sucrose intake by the animals. Post hoc analysis revealed that anhedonic animals significantly decreased their sucrose consumption levels after the first and second weeks of the CMS procedure compared to control and resilient littermates (Fig. 1a). Statistical analysis showed no effect of stress and time on sucrose consumption in resilient subjects (Fig. 1a). Although repeated measures ANOVA suggested a significant effect of stress $\left(F_{2,90}=6.668 ; p<0.01\right)$ and time $\left(F_{2,90}=5.255 ; p<0.05\right)$ on body weight gain/loss of animals in CMS model, further Bonferroni's post hoc analysis did not show any significant difference in weights between all groups of animals neither before the CMS nor after 2 weeks of stress regimen (Fig. 1c). After 2 weeks of CMS, only resilient rats exhibited significantly increased serum CORT levels $\left(F_{2,43}=\right.$ $5.02 ; p<0.01 ; n=15-16 /$ group) compared to control and anhedonic littermates (Fig. 1b). At the same time, Western blot

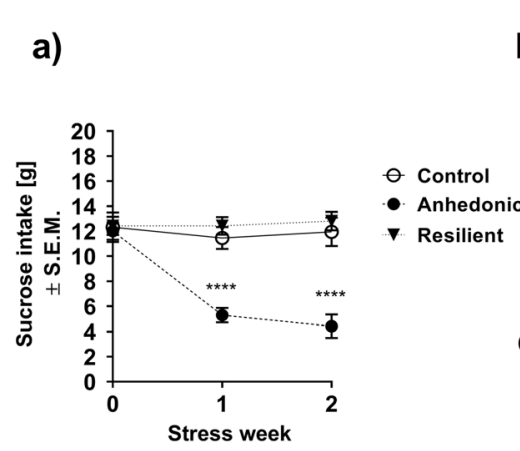

d)

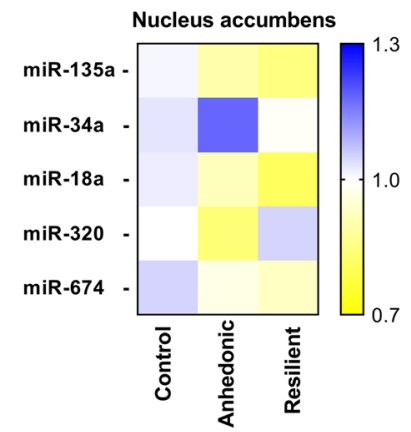

\section{b) \\ c)}
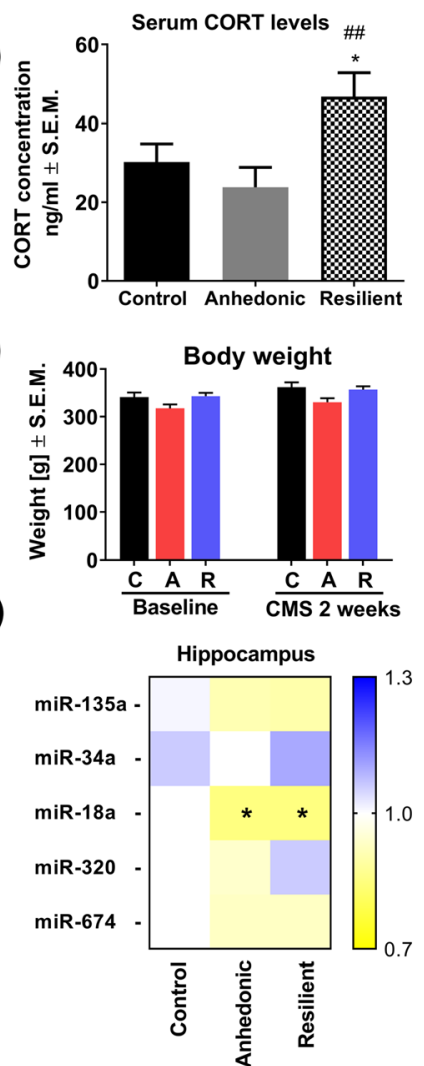

f)

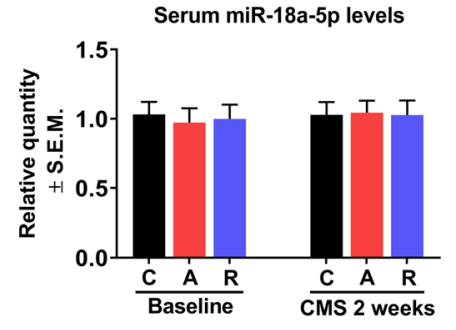

g)

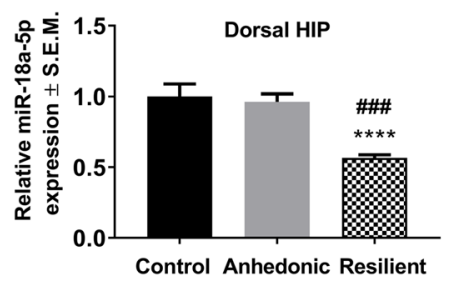

h)

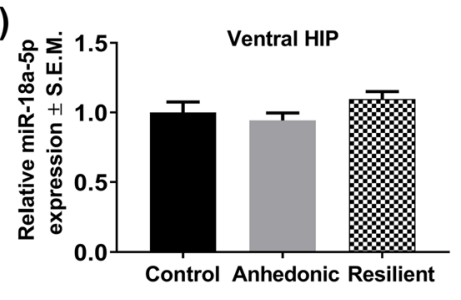

Fig. 1 a The effect of 2 weeks of the CMS procedure on sucrose intake in control, anhedonic and resilient animals. Point " 0 " refers to sucrose intake by all examined animals before the start of CMS. Anhedonic animals significantly decreased their sucrose intake compared to control and resilient rats $(n=16 /$ group), $* * * * p<0.0001$ vs. control and resilient. b Elevated serum levels of CORT in resilient animals ( $n=15-16 /$ group): $* p<0.05$ vs. control, \#\#p<0.01 vs. anhedonic group observed after 2 weeks of CMS. c Time-dependent analysis of body weight gain/loss among stressed and non-stressed animals. Two-way ANOVA followed by Bonferroni's post hoc test showed no changes in body weight in all groups of animals before and after 2 weeks of CMS ( $n=16 /$ group). d Results of the screening analysis of the expression levels of five different miRNAs in the NAcc of stressed and non-stressed animals ( $n=10$ /group). e Results from the screening analysis of the expression levels of five different miRNAs in the HIP of stressed and non-stressed animals.
One-way ANOVA followed by post hoc tests showed a significant decrease in the expression level of miR-18a in resilient and anhedonic rats compared to control littermates $(n=10 /$ group), $* p<0.05$. f Timedependent analysis of serum miR-18a-5p levels among stressed and non-stressed animals. Repeated measures ANOVA followed by Bonferroni's post hoc tests showed no changes in serum levels of miR$18 \mathrm{a}-5 \mathrm{p}$ either before the start of the CMS procedure or during stress exposure in all groups of animals ( $n=5-9 /$ group). g RT-PCR analysis of the expression level of miR18a-5p in dHIP of animals after 2 weeks of CMS. Resilient animals had significantly decreased miR-18a-5p expression in dHIP as compared to control $(* * * * p<0.001)$ and anhedonic $(\# \# p<0.01)$ littermates $(n=12 /$ group $)$. h RT-PCR analysis of the expression level of miR18a-5p in vHIP revealed no alterations across all animals being tested ( $n=12$ /group) 
analysis showed normal levels of glucocorticoid (GR) and mineralocorticoid (MR) receptor proteins in the HIP of all tested animals ( $n=4$ /group) (Supplementary material 2 ).

\section{The Effect of 2 Weeks of CMS on Brain and Serum miR-18a-5p Expression Levels in Rats}

Screening analysis of a set of five different miRNAs (that are reported to be important in the development of the stress response) showed no differences in the expression levels of all tested miRNAs in the NAcc of rats subjected to 2 weeks of CMS (Fig. 1d). However, we found a statistically significant decrease in the expression levels of hippocampal miR-18a-5p in stressed animals ( $F_{2,27}=4.86, p<0.05 ; n=10$ /group) compared to non-stressed controls (Fig. 1e). Our further RT-PCR evaluation of the results obtained from screening analysis revealed that only resilient animals had significantly decreased expression level of miR-18a-5p in the dorsal part of the hippocampus (dHIP) $\left(F_{2,33}=15.60, p<0.0001 ; n=12 /\right.$ group $)$ while no changes were observed in the ventral part (vHIP) $\left(F_{2,33}=1.561, p>0.05 ; n=12\right.$ /group) of above mentioned brain structure as compared to control as well as anhedonic animals (Fig. 1g-h, respectively). In order to examine whether dHIP alterations in the expression level of miR-18a-5p may have a potential to be a peripheral molecular marker of the stress resilience, we performed analysis of serum levels of miR-18a-5p among all tested animals. However, timedependent analysis revealed no significant effect of stress $\left(F_{2,55}=1.10, p>0.05 ; n=5-9 /\right.$ group $)$, time $\left(F_{2,55}=2.19\right.$, $p>0.05 ; n=5-9$ /group), or interaction of stress $\times$ time $\left(F_{2,55}=0.82, p>0.05 ; n=5-9 /\right.$ group $)$ on serum levels of miR-18a-5p in control and stressed animals before the start of the stress regimen (baseline) as well as during the 2 weeks of CMS (Fig. 1f) what indicated that changes in the expression level of miR-18a-5p in dHIP of resilient animals are brainspecific.

\section{Bioinformatic Analysis of Genes Expressed in HIP and Being Regulated by miR18a-5p and Their Biological Function}

In silico analysis, using the freely available online database, MirWalk 2.0 found that miR-18a-5p may potentially interact with mRNA encoding 5- $\mathrm{HT}_{1 \mathrm{~A}} \mathrm{R}$ (Fig. 2a). Moreover, the comparative analysis showed that this potential interaction was reported by different prediction algorithms, i.e., miRWalk, miRanda, and TargetScan (Fig. 2a). Gene enrichment analysis of all potential miR-18a-5p gene targets which are expressed in HIP showed that this microRNA can be significantly involved in the regulation of biological processes relevant to the functioning of the HIP (Fig. 2b) as well as molecular pathways, such as axonogenesis, in both human and rodents (Fig. 2c).

\section{In vitro Validation of the Regulatory Potential of miR-18a-5p on 5-HT ${ }_{1 A} R$ mRNA Expression}

To determine whether miR-18a-5p had the potential to regulate 5- $\mathrm{HT}_{1 \mathrm{~A}} \mathrm{R}$ mRNA expression, we used primary cultures of hippocampal neurons obtained from adult rats that have high levels of endogenous 5- $\mathrm{HT}_{1 \mathrm{~A}} \mathrm{R}$ expression. Adult neuronal cultures have a strong advantage over commonly used embryonic cells because their physiology, pharmacological properties, and even pathophysiology are more comparable to those observed in vivo in brain tissue [40]. Immunocytochemical examination of the purity of neuron cell culture showed that approximately $90 \%$ of the cells were MAP2-positive, and there were no observed GFAP-positive astroglial cells (Fig. 2e), which may overgrow the neuronal culture and therefore disturb the molecular analyses. RT-PCR analysis showed significantly decreased expression levels of mRNA encoding $5-\mathrm{HT}_{1 \mathrm{~A}} \mathrm{R}$ in hippocampal neurons stimulated for $48 \mathrm{~h}$ with $20 \mathrm{nM}$ of miR-18a mimic $\left(F_{2,10}=5.41 ; p<0.05 ; n=4-5 /\right.$ group). Post hoc analysis showed that this effect was statistically significant compared to unstimulated neurons as well as to neurons transfected with $20 \mathrm{nM}$ of Silencer® Select negative control (Fig. 2d).

\section{The Effect of 2 Weeks of CMS on the Expression Level of Hippocampal 5-HT ${ }_{1 A} R$}

One-way ANOVA analysis showed a significant effect of stress exposure on overall hippocampal $5-\mathrm{HT}_{1 \mathrm{~A}} \mathrm{R}$ protein $\left(F_{2,21}=8.06 ; p<0.01 ; n=8 /\right.$ group $)$ as measured by Western blot. Post hoc analysis revealed that stress-resilient subjects had significantly higher hippocampal levels of $5-\mathrm{HT}_{1 \mathrm{~A}} \mathrm{R}$ protein compared to those in control and anhedonic animals (Fig. 3a). Further histological examination with the use of radiolabeled $5-\mathrm{HT}_{1 \mathrm{~A}} \mathrm{R}$ agonist $\left[{ }^{3} \mathrm{H}\right] 8-\mathrm{OH}-\mathrm{DPAT}$ showed that increased $5-\mathrm{HT}_{1 \mathrm{~A}} \mathrm{R}$ levels in the resilient animals were restricted to CA1 $\left(F_{2,17}=17.82, p<0.001 ; n=6-7 /\right.$ group $)$, CA2 $\left(F_{2,15}=12.90, p<0.001 ; n=6 /\right.$ group $)$ and CA3 $\left(F_{2,17}=7.79, p<0.01 ; n=6-7 /\right.$ group $)$ subregions of the dHIP compared to those in control and anhedonic rats (Fig. $3 \mathrm{f}-\mathrm{h}$, respectively). On the other hand, the autoradiographic study did not show altered $5-\mathrm{HT}_{1 \mathrm{~A}} \mathrm{R}$ levels in all examined subregions of the vHIP (Fig. 4e-h). Furthermore, we observed no changes in the expression levels of mRNA encoding $5-\mathrm{HT}_{1 \mathrm{~A}} \mathrm{R}$ in all examined anatomical areas of the dHIP (Fig. 3b-e) and the vHIP (Fig. 4a-d) in either the anhedonic or resilient groups of rats compared to the control group.

\section{The Effect of 2 Weeks of the CMS Procedure on Hippocampal 5-HT and 5-HIAA Levels in Animals}

HPLC analysis showed no differences in hippocampal serotonin (5-HT) concentrations (Fig. 5a) across all groups of 
a)

Comparative bioinformatic analysis of miR-18a - 5HT ${ }_{1 A} \mathrm{R}$ mRNA interaction

\begin{tabular}{|l|l|c|c|l|c|c|c|}
\hline miRNA & MIMATid & Gene CDS & EntrezID & RefseqID & miRWalk & miRanda & Targetscan \\
\hline mo-miR-18a-5p & MIMAT0000787 & Htr1a & 24473 & NM_012585 & 1 & 1 & 1 \\
\hline
\end{tabular}

1- positive interacion revealed by a particular algorithm

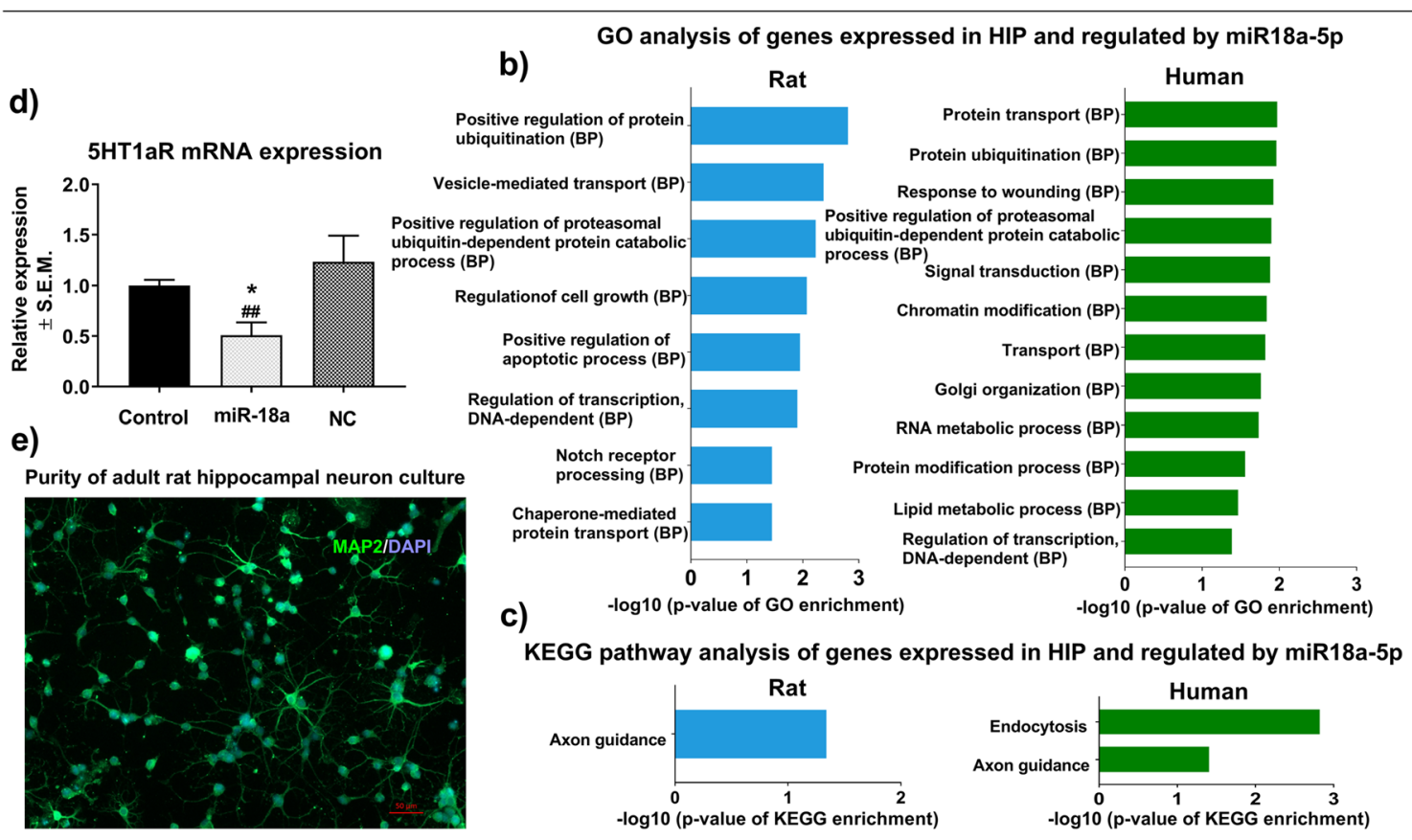

Fig. 2 a Comparative bioinformatic analysis with the use of miRWalk 2.0 software shows that miR-18a-5p is a potential posttranscriptional regulator of mRNA encoding $5-\mathrm{HT}_{1 \mathrm{~A}} \mathrm{R}$. 1 -indicates positive predicted interaction between miR-18a-5p and mRNA encoding $5-\mathrm{HT}_{1 \mathrm{~A}} \mathrm{R}$ as revealed by a particular algorithm. b Gene enrichment analysis revealed that genes potentially regulated by miR-18a-5p and expressed in HIP are significantly involved in different biological processes associated with normal brain functioning in rats (left panel) and humans (green panel). All biological processes were calculated by hypergeometric distribution followed by $p$ value correction for multiple testing. $\mathbf{c}$ KEGG pathway analysis of genes expressed in HIP and regulated by miR-18a-5p revealed that this miR is involved in the regulation of axonogenesis in both humans (right panel) and rats (left panel) and endocytosis in humans

animals. However, we observed that both anhedonic and resilient animals exhibited significantly decreased levels of intraneuronal serotonin metabolite 5-hydroxyindoleacetic acid (5-HIAA) $\left(F_{2,9}=6.74 ; p<0.01 ; n=4\right.$ /group) compared to levels in non-stressed littermates (Fig. 5b). Moreover, only anhedonic individuals showed a diminished ratio of 5HIAA/5-HT in the hippocampus $\left(F_{2,9}=9.66 ; p<0.005 ; n=\right.$ 4/group) compared to the control and resilient groups of rats (Fig. 5c), which suggested that anhedonic but not resilient animals expressed lowered hippocampal 5-HT turnover in response to stressful conditions.

\section{Discussion}

In the present study, we focused on finding potential epigenetic factors and their downstream molecular targets that may be (right panel). KEGG pathways were by hypergeometric distribution followed by $p$ value correction for multiple testing. $\mathbf{d}$ In vitro validation of the regulatory role of miR-18a-5p on the expression level of mRNA encoding $5-\mathrm{HT}_{1 \mathrm{~A}} \mathrm{R}$. RT-PCR analysis shows that neurons transfected with $20 \mathrm{nM}$ of miR-18a-5p expressed significantly lower levels of 5$\mathrm{HT}_{1 \mathrm{~A}} \mathrm{R}$ mRNA compared to non-transfected as well as neurons stimulated with negative control siRNA $(n=4-5),{ }^{*} p<0.05$ vs. control, $\# \# p<0.01$ vs. negative control. e Immunocytochemical examination of the purity of the adult hippocampal neuronal cell culture. Double-staining for MAP2 and GFAP markers revealed that a vast majority of cultured cells were MAP2-positive neurons (green cells). There were no recorded GFAP-positive (orange cells) astroglial cells in the culture

associated with the development of resilient behavior. The resilient phenotype is characterized in individuals who, despite experiencing chronic stress, maintain a positive mood and general psychological balance. Because recent behavioral experiments have demonstrated that most commonly used animal models of depression can generate behaviorally resilient animals [11, 43-45], it has become possible to expand the field of preclinical research on the molecular and biochemical mechanisms underlying "stress-resistant" behaviors. In this work, we used the CMS paradigm, a well-validated animal model of depression [46-48] that, by using different longlasting and mild socio-environmental stressors, mimics prodepressive conditions observed in human life. Based on the analysis of sucrose intake by the rats, which is a core marker of responsiveness to reward stimuli, we were able to discriminate resilient and anhedonic animals (Fig. 1a). Decreased sucrose intake by stress-vulnerable animals and, at the same 

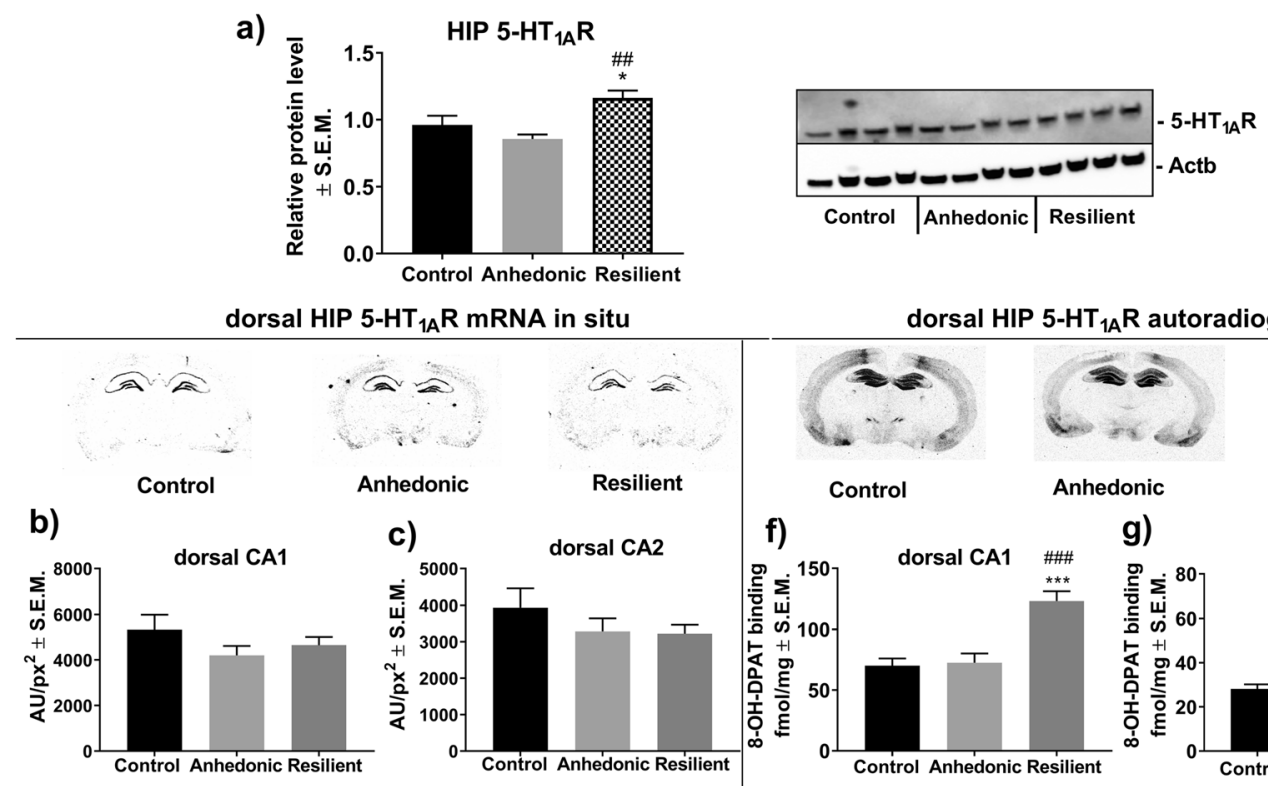

d)

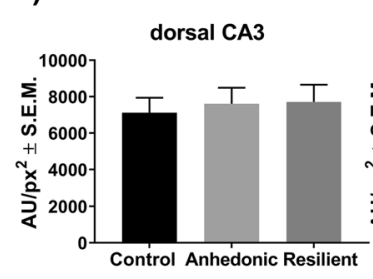

e)

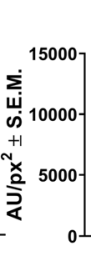

dorsal DG

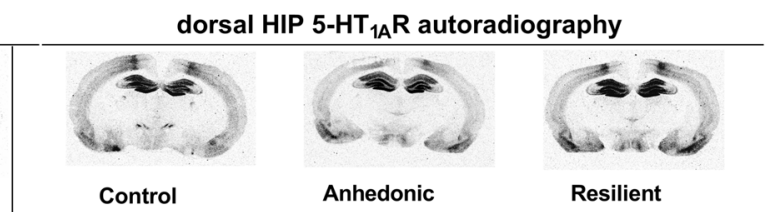

f)

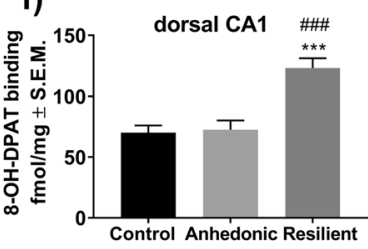

g) dorsal CA2

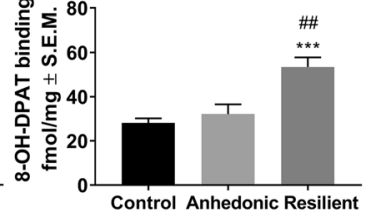

h)

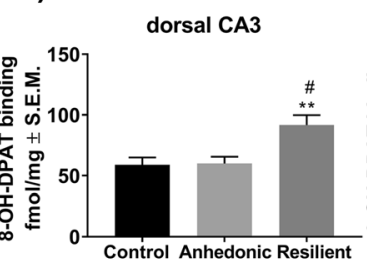

i)

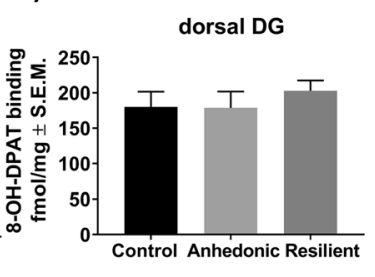

Fig. 3 a Western blot analysis showed increased hippocampal 5- $\mathrm{HT}_{1 \mathrm{~A}} \mathrm{R}$ protein levels in resilient animals; ${ }^{*} p<0.05$ vs. control and \#\#p $<0.01$ vs. resilient group of rats ( $n=8 /$ group). The left lower panel represents results from an in situ hybridization study of the expression level of mRNA encoding 5- $\mathrm{HT}_{1 \mathrm{~A}} \mathrm{R}$ in b CA1, c CA2, d CA3, and e dentate gyrus (DG) subregions of the dHIP ( $n=5-10 /$ group). The right lower panel represents the results from $\left[{ }^{3} \mathrm{H}\right] 8-\mathrm{OH}-\mathrm{DPAT}$ agonist binding to 5-

time, a lack of differences in body weight gain between all tested groups of rats during 2 weeks of CMS (Fig. 1c) indicate that this test measures hedonistic aspects of behavior rather than overall food intake. The CMS paradigm, by generating subjects with different behavioral coping strategies, mimics the natural heterogeneity of stress responses observed among humans. Further biochemical analysis revealed that resilient, but not anhedonic, animals exhibited significantly elevated serum CORT level after 2 weeks of CMS (Fig. 1b). At the same time, all groups of rats had normal levels of GR and MR in the hippocampus (Supplementary materials 2). Fine-tuned CORT release increases the energetic and metabolic rate of the organism and promotes coping with adversity [49]. Therefore, increased serum levels of CORT in resilient rats may reflect their metabolic arousal, which in turn may contribute to a more effective coping strategy in the face of stress. These observations are consistent with our previous work where we showed that resilient animals responded to 2 weeks of CMS by an elevated level of serum CORT and this response was normalized to the control level during long-lasting stress,
$\mathrm{HT}_{1 \mathrm{~A}} \mathrm{R}$ in $\mathbf{f} \mathrm{CA} 1, \mathbf{g ~ C A} 2, \mathbf{h} \mathrm{CA} 3$, and $\mathbf{i}$ DG subregions of the hippocampus. Resilient animals exhibited increased $\left[{ }^{3} \mathrm{H}\right] 8-\mathrm{OH}-\mathrm{DPAT}$ binding to $5-\mathrm{HT}_{1 \mathrm{~A}} \mathrm{R}$ in $\mathbf{f} \mathrm{CA} 1, \mathbf{g} \mathrm{CA} 2$, and $\mathbf{h} \mathrm{CA} 3$ subregions of the dHIP compared to non-stressed and anhedonic littermates $(n=6-7 /$ group), ${ }^{* *} p<0.01, * * * p<0.001$ vs. control; $\# p<0.05, \# \# p<0.01$, $\# \#$ \# $<0.001$ vs. anhedonic

i.e., 7 weeks of CMS [11]. Moreover, recent reports have shown that depression, as well as vulnerability to stress (in animal models of depression), may be associated not only with exacerbated hypothalamus-adrenal-pituitary (HPA) axis activity but also with blunted cortisol/corticosterone release [50-52]. Normal levels of hippocampal GR and MR observed across all animals being tested in our study may indicate that the CORT response in the resilient animals was not exaggerated and thus beneficial. It should be mentioned that we measured GR and MR protein levels in whole hippocampi, and therefore some potential changes specific only for dHIP or vHIP could have been diluted by using pooled tissue samples. It has been reported, however, that basal level of GR is higher in dHIP while MR level is higher in vHIP [53]. Thus, by measuring the levels of both receptors in HIP samples, it can be postulated that potential changes would come from the region with higher expression of either GR or MR. Nevertheless, the effect of different stress phenotype on the expression of GR and MR in subregions of the hippocampus needs further detailed research. 
ventral HIP 5-HT 1 R mRNA in situ
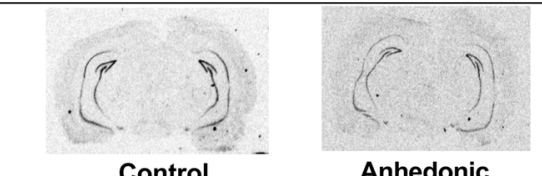

Anhedonic

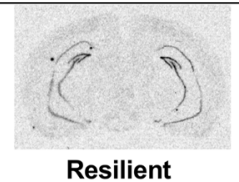

a)

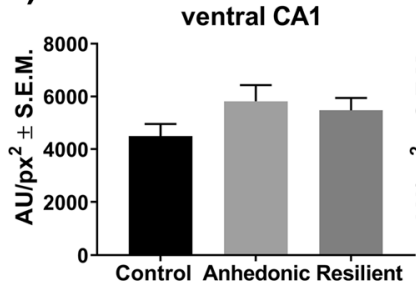

c)

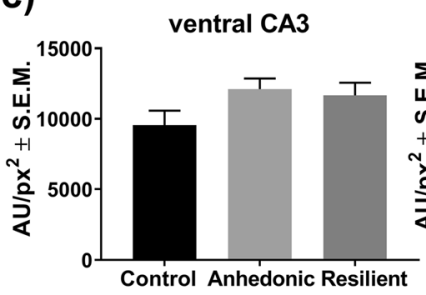

b)

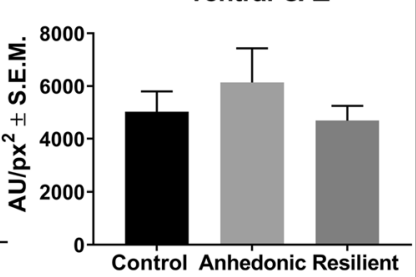

d)

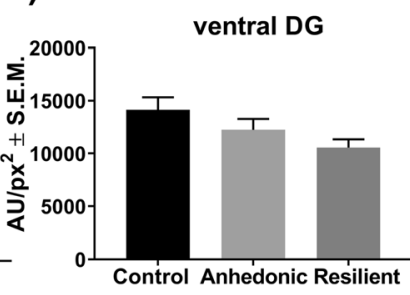

ventral HIP 5-HT $1 \mathrm{~A}$ autoradiography

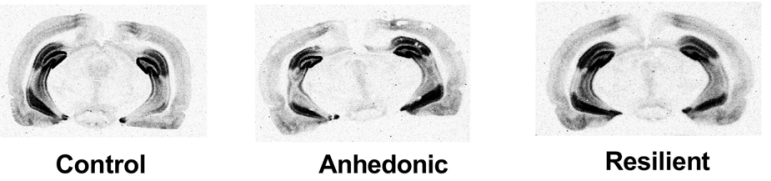

e) ventral CA1

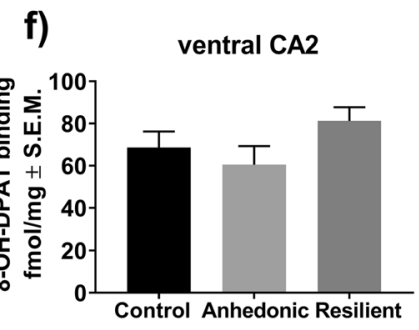

h)

g)

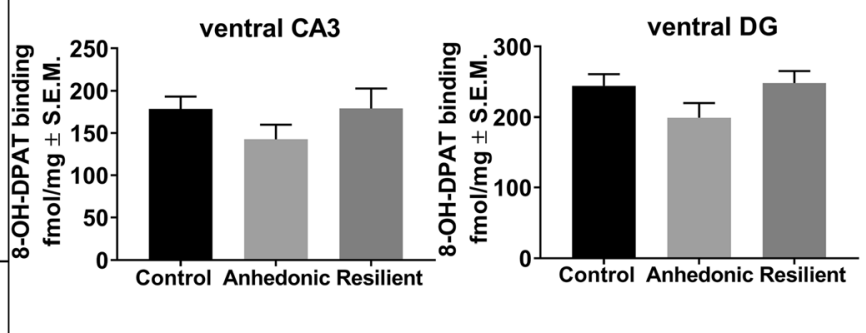

Fig. 4 Left panel represents results from an in situ hybridization study of the expression level of mRNA encoding $5-\mathrm{HT}_{1 \mathrm{~A}} \mathrm{R}$ in a CA1, b CA2, c CA3, and d dentate gyrus (DG) subregions of the vHIP ( $n=5-8$ /group). The right panel represents the results from $\left[{ }^{3} \mathrm{H}\right] 8-\mathrm{OH}-\mathrm{DPAT}$ agonist

miRNA expression screening analysis suggested that stressful conditions may alter the expression level of miR$18 \mathrm{a}-5 \mathrm{p}$ in the HIP of experimental animals (Fig. 1e). A panel of a set of five miRNAs was chosen based on a literature survey and based on our previous results showing that all of the miRNAs examined here potentially regulate serotonergic transmission in the mesocortical circuit of resilient animals [22]. Our further RT-PCR evaluation of screening analysis revealed that only resilient animals had significantly decreased the expression level of miR-18a-5p as compared to control and anhedonic animals and this alteration was binding to $5-\mathrm{HT}_{1 \mathrm{~A}} \mathrm{R}$ in $\mathbf{e} \mathrm{CA} 1, \mathbf{f} \mathrm{CA} 2, \mathbf{g ~ C A} 3$, and $\mathbf{h}$ DG subregions of the vHIP ( $n=6-9$ /group). One-way ANOVA showed no statistically significant alterations in mRNA expression and $5-\mathrm{HT}_{1 \mathrm{~A}} \mathrm{R}$ levels in all examined subregions of the vHIP in animals after 2 weeks of CMS a)

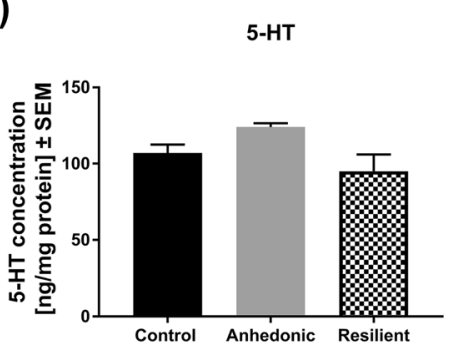

b)

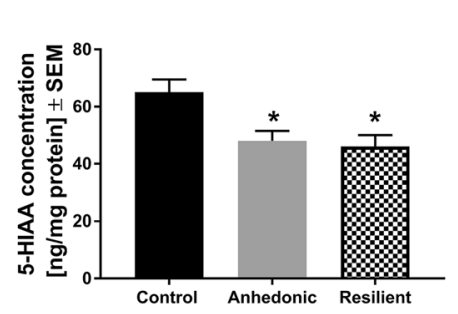

c)

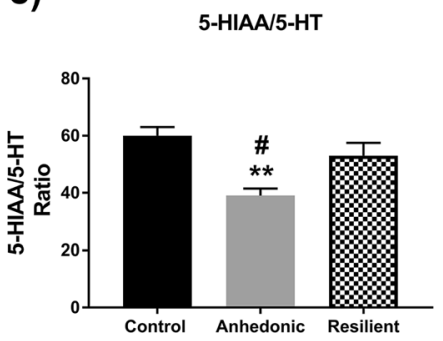

Fig. 5 The effect of 2 weeks of CMS on serotonergic balance in the HIP of stressed and non-stressed rats. a Represents hippocampal 5-HT concentrations in all groups of animals; b 2 weeks of CMS was associated with a significant decrease in the hippocampal 5-HIAA exclusively restricted to the dHIP (Fig. 1g). It is worth noting that, in our previous study, we observed reduced the expression level of miR-18a-5p in the prefrontal cortex (PCx), together with increased expression of the same miR in the ventral tegmental area (VTA) of resilient animals [22]. Both brain structures have influential effects on different parts of the hippocampus. vHIP receives reach innervation from the VTA [53] while dHIP mainly from the mPCx [54]. Similar direction of changes in the expression level of miR-18a-5p observed in the dHIP and PCx may confirm functional and anatomical connectivity of both brain areas. Our findings suggest that

levels in anhedonic and resilient animals, $* p<0.05$ vs. control $(n=4 /$ group); c anhedonic animals exhibited a significantly decreased 5-HT/ 5-HIAA ratio in the HIP compared to control and resilient rats $(n=4$ / group), $* * p<0.01$ vs. control and $\# p<0.05$ vs. resilient group 
various regulations of miR-18a-5p expression in resilient subjects may depend on a unique transcriptomic landscape of a particular brain structure or even cell type.

Different gene expression patterns, anatomical projections, as well as specific functional outcomes suggest that hippocampus can be divided into at least two separate zones, i.e., the dHIP and the vHIP. The dHIP has been classified as a region mainly responsible for processing different types of memory as well as for cognitive functions and contextual fear. On the other hand, the functioning of the vHIP has been correlated with brain structures involved in stress and emotion [55-57]. Thus, both parts of the hippocampus are profoundly but differentially involved in processing of a wide range of psycho-vegetative aspects related to coping with stressful events. In our work, we observed that CMS had a strong impact on dHIP of resilient animals. This observation is consistent with previous work which has also reported that chronic unpredictable stress had a different impact on the structure and function of the dHIP versus vHIP in rats [58]. Another recent study by Liu and co-workers has shown that chronic social defeat stress caused post-stress microstructural alterations in the right dHIP of resilient mice. This indicates that the dHIP may be important in stress-resilient phenotypes [59].

According to our bioinformatic and in vitro analyses, miR$18 \mathrm{a}-5 \mathrm{p}$ has the potential to post-transcriptionally and negatively regulate mRNA encoding $5-\mathrm{HT}_{1 \mathrm{~A}} \mathrm{R}$ (Fig. 2a, d), which is highly expressed in the HIP but not in the NAcc. These observations indicated that regulatory features of miR-18a-5p are important in the functioning of the dHIP under stress. It is also important to note that the nucleotide sequence of miR$18 \mathrm{a}-5 \mathrm{p}$ is conserved among mammals. This fact makes miR$18 \mathrm{a}-5 \mathrm{p}$ a good candidate in translational studies because we can find the same miR-18a-5p nucleotide sequence, and therefore similar biological properties among rodents and humans. This conclusion can be supported by our gene ontology analyses which showed that miR-18a-5p may regulate a set of genes involved in biological processes, such as axonogenesis, which are important in normal hippocampal functioning in both human and rodents (Fig. 2b-c). miRNAs are described as negative posttranscriptional regulators that can inhibit the translation of targeted mRNA or decrease its level [8]. However, decreased cellular levels of miRNA may not result in higher expression of targeted mRNA. This is because miRNAs do not interfere with the transcriptional activity of the cell. This phenomenon may explain our results showing that a lowered level of miR-18a-5p in the dHIP of stressresilient rats was accompanied by an increased level of 5$\mathrm{HT}_{1 \mathrm{~A}} \mathrm{R}$ protein, but not mRNA (Fig. 3a-i). Interestingly, we did not observe altered expression of miR-18a-5p in vHIP which was accompanied by normal levels of mRNA (Fig. $4 \mathrm{a}-\mathrm{d}$ ) and $5-\mathrm{HT}_{1 \mathrm{~A}} \mathrm{R}$ protein (Fig. $4 \mathrm{e}-\mathrm{h}$ ) in the abovementioned hippocampal substructure. This observation suggests that molecular changes at the level of miR-18a-5p and its downstream target $5-\mathrm{HT}_{1 \mathrm{~A}} \mathrm{R}$ in the dHIP, but not vHIP, may be particularly important in the development of resilient phenotype. Our results partially supported other researches by Pan and co-workers who showed that chronically stressed animals had significantly decreased expression levels of miR-18a-5p in the hippocampus, which was reversed by chronic duloxetine treatment [23]. In their study, authors did not differentiate stressed animals into vulnerable and resilient groups, which could mask some molecular changes specific for each behavioral trait. Chronic treatment with duloxetinea selective serotonin and noradrenalin reuptake inhibitormay alter hippocampal $5-\mathrm{HT}_{1 \mathrm{~A}} \mathrm{R}$ density, what in turn may evoke a molecular response at the level of miR-18a-5p expression. However, this phenomenon needs further research, especially that pharmacological profile of duloxetine is wide, and thus may secondarily influence many different molecular pathways including miRNA transcription.

We also analyzed whether decreased expression of miR$18 \mathrm{a}-5 \mathrm{p}$ in the brain may be reflected in the peripheral blood of stressed animals. To test this, we collected serum samples from all tested animals before the start of the CMS and after 2 weeks of the stress procedure. However, we did not find any change in the serum level of miR-18a-5p among all animals (Fig. 1f). This observation suggests that stress specifically influences only brain-derived miR-18a-5p.

Among all currently known serotonin receptors, $5-\mathrm{HT}_{1 \mathrm{~A}} \mathrm{Rs}$ are most abundantly expressed in the hippocampus [60]. The important involvement of hippocampal $5-\mathrm{HT}_{1 \mathrm{~A}} \mathrm{Rs}$ in the pathomechanisms of stress-related mood disorders has been widely described in clinical and preclinical studies. Jovanovic and co-workers, by using fMRI analysis, have shown reduced $5-\mathrm{HT}_{1 \mathrm{~A}} \mathrm{R}$ binding in the anterior cingulate cortex and the hippocampus of chronically stressed persons compared to nonstressed subjects [61]. Animal studies seem to confirm the involvement of 5- $\mathrm{HT}_{1 \mathrm{~A}} \mathrm{R}$ activity in the pathogenesis of depression. For instance, $5-\mathrm{HT}_{1 \mathrm{~A}}$ heteroreceptor depletion in developing mice resulted in decreased mobility and increased behavioral despair in adulthood [62]. We revealed that resilient animals had significantly increased $5-\mathrm{HT}_{1 \mathrm{~A}} \mathrm{R}$ in the CA1 (Fig. 3f), CA2 (Fig. 3g), and CA3 regions of the dHIP (Fig. 3h). Our observations are inconsistent with the previous study which has reported that activation of 5-HT1aRs in the dHIP by $8-\mathrm{OH}-\mathrm{DPAT}$ - a potent 5 -HT1aR agonist or by treatment with imipramine attenuated the development of learned helplessness. Thus, activation of post-synaptic 5-HT1a receptors in the dHIP mediated adaptation to severe inescapable stress [63]. Other works have shown that that intrahippocampal infusion of sub-effective doses 8-OH-DPAT enhanced the antidepressant effects of fish oil in supplemented animals [64]. Moreover, it has been reported that $5-\mathrm{HT}_{1 \mathrm{~A}}$ receptor density was significantly higher in the $\mathrm{CA} 1$ region of the hippocampus in the Flinders stress-resistant line of rats (FRL) compared to stress-sensitive animal strains [36]. 
Therefore, the increased level of hippocampal 5-HT ${ }_{1 A} \mathrm{R}$ in resilient animals may represent a molecular marker that exerts a protective action on limbic functioning and serotonergic balance. To explore this phenomenon, we measured the concentration of 5-HT and its metabolite 5-HIAA in the hippocampi of animals subjected to 2 weeks of CMS. We found that both groups of stressed rats had lower levels of 5-HIAA (Fig. 5b) with no changes in 5-HT concentration (Fig. 5a). Additionally, we found that only anhedonic animals exhibited a reduced hippocampal 5-HT/5-HIAA ratio, which reflects the diminished serotonergic turnover observed in vulnerable rats (Fig. 5c). This observation is consistent with previous experiments showing decreased serotonin turnover in different brain areas of bulbectomized mice in an animal model of depression [65]. Resilient animals, in contrast, exhibited a normal 5-HT/5-HIAA ratio, and thus maintained serotonergic homeostatic balance in the face of stress. To sum up, we showed that the resilient (but not anhedonic) phenotype is associated with increased 5- $\mathrm{HT}_{1 \mathrm{~A}} \mathrm{R}$ levels exclusively in the dHIP. This molecular characteristic may be under the regulatory control of hippocampal miR-18a-5p expression. As a result, these two molecular factors may contribute to maintaining hippocampal serotonergic balance in the face of adversity as observed in resilient animals.

Funding Information This study is supported by Grant No. DEC-2015/ 17/N/NZ4/02798, National Science Centre, Poland; Grant No. DEC2012/07/B/NZ7/01164, National Science Centre, Poland; Statutory Activity of Institute of Pharmacology Polish Academy of Sciences, Poland; Statutory Activity of Department of General Biochemistry, Jagiellonian University K/ZDS/007440.

\section{Compliance with Ethical Standards}

All behavioral experiments were approved by the II Local Bioethics Commission (Krakow, Poland) and were carried out in accordance with EU Directive 2010/63/EU for animal experiments.

Conflict of Interest The authors declare that they have no conflict of interest.

Open Access This article is distributed under the terms of the Creative Commons Attribution 4.0 International License (http:// creativecommons.org/licenses/by/4.0/), which permits unrestricted use, distribution, and reproduction in any medium, provided you give appropriate credit to the original author(s) and the source, provide a link to the Creative Commons license, and indicate if changes were made.

\section{References}

1. Walker FR, Pfingst K, Carnevali L, Sgoifo A, Nalivaiko E (2017) In the search for integrative biomarker of resilience to psychological stress. Neurosci Biobehav Rev 74(Pt B):310-320. https://oi.org/ 10.1016/j.neubiorev.2016.05.003
2. Rutter M (1985) Resilience in the face of adversity: protective factors and resistance to psychiatric disorder. Br J Psychiatry 147:598611

3. Consoloni JL, Ibrahim EC, Lefebvre MN, Zendjidjian X, Olié E, Mazzola-Pomietto P, Desmidt T, Samalin L et al (2018) Serotonin transporter gene expression predicts the worsening of suicidal ideation and suicide attempts along a long-term follow-up of a Major Depressive Episode. Eur Neuropsychopharmacol 28(3):401-414. https://doi.org/10.1016/j.euroneuro.2017.12.015

4. Szyf M (2015) Epigenetics, a key for unlocking complex CNS disorders? Therapeutic implications. Eur Neuropsychopharmacol 25(5):682-702. https://doi.org/10.1016/j.euroneuro.2014.01.009

5. Leonardo ED, Hen R (2006) Genetics of affective and anxiety disorders. Annu Rev Psychol 57:117-137

6. Caspi A, Sugden K, Moffitt TE, Taylor A, Craig IW, Harrington H, McClay J, Mill J et al (2003) Influence of life stress on depression: moderation by a polymorphism in the 5-HTT gene. Science 301 : 386-389

7. Xu B, Hsu PK, Karayiorgou M, Gogos JA (2012) MicroRNA dysregulation in neuropsychiatric disorders and cognitive dysfunction. Neurobiol Dis 46(2):291-301. https://doi.org/10.1016/j.nbd.2012. 02.016

8. Gebert LFR, MacRae IJ (2018) Regulation of microRNA function in animals. Nat Rev Mol Cell Biol. https://doi.org/10.1038/s41580018-0045-7

9. Smalheiser NR, Lugli G, Zhang H, Rizavi H, Cook EH, Dwivedi Y (2014) Expression of microRNAs and other small RNAs in prefrontal cortex in schizophrenia, bipolar disorder and depressed subjects. PLoS One 9(1):e86469. https://doi.org/10.1371/journal.pone. 0086469

10. Liu Y, Liu D, Xu J, Jiang H, Pan F (2017) Early adolescent stressinduced changes in prefrontal cortex miRNA-135a and hippocampal miRNA-16 in male rats. Dev Psychobiol 59(8):958-969. https://doi.org/10.1002/dev.21558

11. Zurawek D, Kusmider M, Faron-Gorecka A, Gruca P, Pabian P, Kolasa M, Solich J, Szafran-Pilch K et al (2016) Time-dependent miR-16 serum fluctuations together with reciprocal changes in the expression level of miR-16 in mesocortical circuit contribute to stress resilient phenotype in chronic mild stress - an animal model of depression. Eur Neuropsychopharmacol 26(1):23-36. https:// doi.org/10.1016/j.euroneuro.2015.11.013

12. Bai M, Zhu X, Zhang Y, Zhang S, Zhang L, Xue L, Yi J, Yao S et al (2012) Abnormal hippocampal BDNF and miR-16 expression is associated with depression-like behaviors induced by stress during early life. PLoS One 7(10):e46921. https://doi.org/10.1371/journal. pone. 0046921

13. Meerson A, Cacheaux L, Goosens KA, Sapolsky RM, Soreq H, Kaufer D (2010) Changes in brain MicroRNAs contribute to cholinergic stress reactions. J Mol Neurosci 40(1-2):47-55. https://doi. org/10.1007/s12031-009-9252-1

14. Rinaldi A, Vincenti S, De Vito F, Bozzoni I, Oliverio A, Presutti C, Fragapane P, Mele A (2010) Stress induces region specific alterations in microRNAs expression in mice. Behav Brain Res 208(1): 265-269. https://doi.org/10.1016/j.bbr.2009.11.012

15. Li YJ, Xu M, Gao ZH, Wang YQ, Yue Z, Zhang YX, Li XX, Zhang $C$ et al (2013) Alterations of serum levels of BDNF-related miRNAs in patients with depression. PLoS One 8(5):e63648. https://doi.org/10.1371/journal.pone.0063648

16. Bocchio-Chiavetto L, Maffioletti E, Bettinsoli P, Giovannini C, Bignotti S, Tardito D, Corrada D, Milanesi L et al (2013) Blood microRNA changes in depressed patients during antidepressant treatment. Eur Neuropsychopharmacol 23(7):602-611. https://doi. org/10.1016/j.euroneuro.2012.06.013

17. Baudry A, Mouillet-Richard S, Schneider B, Launay JM, Kellermann O (2010) miR-16 targets the serotonin transporter: a 
new facet for adaptive responses to antidepressants. Science 329(5998):1537-1541. https://doi.org/10.1126/science.1193692

18. Blank T, Nijholt I, Spiess J (2004) Molecular determinants mediating effects of acute stress on hippocampus-dependent synaptic plasticity and learning. Mol Neurobiol 29:131-138. https://doi.org/10. 1385/MN:29:2:131

19. Francis TC, Lobo MK (2017) Emerging role for nucleus accumbens medium spiny neuron subtypes in depression. Biol Psychiatry 81(8):645-653. https://doi.org/10.1016/j.biopsych.2016.09.007

20. Uchida S, Nishida A, Hara K, Kamemoto T, Suetsugi M, Fujimoto M, Watanuki T, Wakabayashi Y et al (2008) Characterization of the vulnerability to repeated stress in Fischer 344 rats: possible involvement of microRNA-mediated down-regulation of the glucocorticoid receptor. Eur J Neurosci 27(9):2250-2261. https://doi.org/10. 1111/j.1460-9568.2008.06218.x

21. Xu J, Wang R, Liu Y, Liu D, Jiang H, Pan F (2017) FKBP5 and specific microRNAs via glucocorticoid receptor in the basolateral amygdala involved in the susceptibility to depressive disorder in early adolescent stressed rats. J Psychiatr Res 95:102-113. https:// doi.org/10.1016/j.jpsychires.2017.08.010

22. Zurawek D, Kusmider M, Faron-Gorecka A, Gruca P, Pabian P, Solich J, Kolasa M, Papp M et al (2017) Reciprocal MicroRNA expression in mesocortical circuit and its interplay with serotonin transporter define resilient rats in the chronic mild stress. MolNeurobiol. 54(8):5741-5751. https://doi.org/10.1007/s12035016-0107-9

23. Pan B, Liu Y (2015) Effects of duloxetine on microRNA expression profile in frontal lobe and hippocampus in a mouse model of depression. Int J Clin Exp Pathol 8(11):15454-15461

24. Andolina D, Di Segni M, Accoto A, Lo Iacono L, Borreca A, Ielpo D, Berretta N, Perlas E et al (2018) MicroRNA-34 contributes to the stress-related behavior and affects 5 -HT prefrontal/GABA amygdalar system through regulation of corticotropin-releasing factor receptor 1. Mol Neurobiol 55(9):7401-7412. https://doi.org/10. 1007/s12035-018-0925-Z

25. Haramati S, Navon I, Issler O, Ezra-Nevo G, Gil S, Zwang R, Hornstein E, Chen A (2011) MicroRNA as repressors of stressinduced anxiety: the case of amygdalar miR-34. J Neurosci 31(40):14191-14203. https://doi.org/10.1523/JNEUROSCI

26. Wan Y, Liu Y, Wang X, Wu J, Liu K, Zhou J, Liu L, Zhang C (2015) Identification of differential microRNAs in cerebrospinal fluid and serum of patients with major depressive disorder. PLoS One 10(3): e0121975. https://doi.org/10.1371/journal.pone.0121975

27. Issler O, Haramati S, Paul ED, Maeno H, Navon I, Zwang R, Gil S, Mayberg HS et al (2014) MicroRNA 135 is essential for chronic stress resiliency, antidepressant efficacy, and intact serotonergic activity. Neuron. 83(2):344-360. https://doi.org/10.1016/j.neuron. 2014.05.042

28. Mannironi C, Camon J, De Vito F, Biundo A, De Stefano ME, Persiconi I, Bozzoni I, Fragapane P et al (2013) Acute stress alters amygdala microRNA miR-135a and miR-124 expression: inferences for corticosteroid dependent stress response. PLoS One 8(9):e73385. https://doi.org/10.1371/journal.pone.0073385

29. Camkurt MA, Acar Ș, Coșkun S, Güneș M, Güneș S, Y1lmaz MF, Görür A, Tamer L (2015) Comparison of plasma MicroRNA levels in drug naive, first episode depressed patients and healthy controls. J Psychiatr Res 69:67-71. https://doi.org/10.1016/j.jpsychires. 2015.07.023

30. White RE, Giffard RG (2012) MicroRNA-320 induces neurite outgrowth by targeting ARPP-19. Neuroreport. 23(10):590-595. https://doi.org/10.1097/WNR.0b013e3283540394

31. Balakathiresan NS, Chandran R, Bhomia M, Jia M, Li H, Maheshwari RK (2014) Serum and amygdala microRNA signatures of posttraumatic stress: fear correlation and biomarker potential. J Psychiatr Res 57:65-73. https://doi.org/10.1016/j.jpsychires. 2014.05.020
32. Drevets WC, Frank E, Price JC, Kupfer DJ, Holt D, Greer PJ, Huang Y, Gautier C et al (1999) PET imaging of serotonin 1A receptor binding in depression. Biol Psychiatry 46:1375-1387

33. Watanabe Y, Sakai RR, McEwen BS, Mendelson S (1993) Stress and antidepressant effects on hippocampal and cortical 5-HT1A and 5-HT2 receptors and transport sites for serotonin. Brain Res 615(1):87-94

34. Artigas F (2013) Serotonin receptors involved in antidepressant effects. Pharmacol Ther 137(1):119-131. https://doi.org/10.1016/j. pharmthera.2012.09.006

35. Mineur YS, Einstein EB, Bentham MP, Wigestrand MB, Blakeman S, Newbold SA, Picciotto MR (2015) Expression of the 5-HT1A serotonin receptor in the hippocampus is required for social stress resilience and the antidepressant-like effects induced by the nicotinic partial agonist cytisine. Neuropsychopharmacology. 40(4): 938-946. https://doi.org/10.1038/npp.2014.269

36. Nishi K, Kanemaru K, Diksic M (2009) A genetic rat model of depression, Flinders sensitive line, has a lower density of 5 HT(1A) receptors, but a higher density of 5-HT(1B) receptors, compared to control rats. Neurochem Int 54(5-6):299-307. https://doi.org/10.1016/j.neuint.2008.12.011

37. Richardson-Jones JW, Craige CP, Guiard BP, Stephen A, Metzger KL, Kung HF, Gardier AM, Dranovsky A et al (2010) 5-HT1A autoreceptor levels determine vulnerability to stress and response to antidepressants. Neuron. 65(1):40-52. https://doi.org/10.1016/j. neuron.2009.12.003

38. Dweep H, Sticht C, Pandey P, Gretz N (2011) miRWalk-database: prediction of possible miRNA binding sites by "walking" the genes of three genomes. J Biomed Inform 44:839-847

39. Tabas-Madrid D, Nogales-Cadenas R, Pascual-Montano A (2012) GeneCodis3: a non-redundant and modular enrichment analysis tool for functional genomics. Nucleic Acids Res:W478-W483. https://doi.org/10.1093/nar/gks402

40. Brewer GJ, Torricelli JR (2007) Isolation and culture of adult neurons and neurospheres. Nat Protoc 2(6):1490-1498

41. Schiller L, Jähke M, Kretzschmar M, Brust P, Oehler J (2003) Autoradiographic analyses of 5-HT1A and 5-HT2A receptors after social isolation in mice. Brain Res 980:169-178. https://doi.org/10. 1016/s0006-8993(03)02832-4

42. Antkiewicz-Michaluk L, Romańska I, Wąsik A, Michaluk J (2017) Antidepressant-like effect of the endogenous neuroprotective amine, 1MeTIQ in clonidine-induced depression: behavioral and neurochemical studies in rats. Neurotox Res 32(1):94-106. https://doi.org/10.1007/s12640-017-9715-z

43. Mul JD, Soto M, Cahill ME, Ryan RE, Takahashi H, So K, Zheng J, Croote DE et al (2018) Voluntary wheel running promotes resilience to chronic social defeat stress in mice: a role for nucleus accumbens $\Delta$ FosB. Neuropsychopharmacology. https://doi.org/ 10.1038/s41386-018-0103-Z

44. Zhang Y, Wang Y, Lei H, Wang L, Xue L, Wang X, Zhu X (2017) Optimized animal model to mimic the reality of stress-induced depression in the clinic. BMC Psychiatry 17(1):171. https://doi.org/ 10.1186/s12888-017-1335-x

45. Palmfeldt J, Henningsen K, Eriksen SA, Müller HK, Wiborg O (2016) Protein biomarkers of susceptibility and resilience to stress in a rat model of depression. Mol Cell Neurosci 74:87-95. https:// doi.org/10.1016/j.mcn.2016.04.001

46. Csabai D, Wiborg O, Czéh B (2018) Reduced synapse and axon numbers in the prefrontal cortex of rats subjected to a chronic stress model for depression. Front Cell Neurosci 12:24. https://doi.org/10. 3389/fncel.2018.00024

47. Gaignier F, Legrand-Frossi C, Stragier E, Mathiot J, Merlin JL, Cohen-Salmon C, Lanfumey L, Frippiat JP (2018) A model of chronic exposure to unpredictable mild socio-environmental stressors replicates some spaceflight-induced immunological 
changes. Front Physiol 9:514. https://doi.org/10.3389/fphys.2018. 00514

48. Zhu S, Shi R, Wang J, Wang JF, Li XM (2014) Unpredictable chronic mild stress not chronic restraint stress induces depressive behaviours in mice. Neuroreport. 25(14):1151-1155. https://doi. org/10.1097/WNR.0000000000000243

49. Morris MC, Rao U (2014) Cortisol response to psychosocial stress during a depressive episode and remission. Stress. 17(1):51-58. https://doi.org/10.3109/10253890.2013.857398

50. Cohen H, Zohar J, Gidron Y, Matar MA, Belkind D, Loewenthal U, Kozlovsky N, Kaplan Z (2006) Blunted HPA axis response to stress influences susceptibility to posttraumatic stress response in rats. Biol Psychiatry 59(12):1208-1218. https://doi.org/10.1016/j. biopsych.2005.12.003

51. Huber TJ, Issa K, Schik G, Wolf OT (2006) The cortisol awakening response is blunted in psychotherapy inpatients suffering from depression. Psychoneuroendocrinology. 31(7):900-904. https://doi. org/10.1016/j.psyneuen.2006.03.005

52. Kudielka BM, Wüst S (2010) Human models in acute and chronic stress: assessing determinants of individual hypothalamuspituitary-adrenal axis activity and reactivity. Stress. 13(1):1-14. https://doi.org/10.3109/10253890902874913

53. Strange BA, Witter MP, Lein ES, Moser EI (2014) Functional organization of the hippocampal longitudinal axis. Nat Rev Neurosci 15(10):655-669. https://doi.org/10.1038/nrn3785

54. Wirt RA, Hyman JM (2017) Integrating spatial working memory and remote memory: interactions between the medial prefrontal cortex and hippocampus. Brain Sci 7(4). https://doi.org/10.3390/ brainsci7040043

55. Floriou-Servou A, von Ziegler L, Stalder L, Sturman O, Privitera M, Rassi A, Cremonesi A, Thöny B et al (2018) Distinct proteomic, transcriptomic, and epigenetic stress responses in dorsal and ventral hippocampus. Biol Psychiatry 84(7):531-541. https://doi.org/10. 1016/j.biopsych.2018.02.003

56. Gulyaeva NV (2018) Functional neurochemistry of the ventral and dorsal hippocampus: stress, depression, dementia and remote hippocampal damage. Neurochem Res. https://doi.org/10.1007/ s11064-018-2662-0

57. Fanselow MS, Dong HW (2010) Are the dorsal and ventral hippocampus functionally distinct structures? Neuron. 65(1):7-19. https://doi.org/10.1016/j.neuron.2009.11.031
58. Pinto V, Costa JC, Morgado P, Mota C, Miranda A, Bravo FV, Oliveira TG, Cerqueira JJ et al (2015) Differential impact of chronic stress along the hippocampal dorsal-ventral axis. Brain Struct Funct 220(2):1205-1212. https://doi.org/10.1007/s00429-014-0713-0

59. Liu X, Yuan J, Guang Y, Wang X, Feng Z (2018) Longitudinal in vivo diffusion tensor imaging detects differential microstructural alterations in the hippocampus of chronic social defeat stresssusceptible and resilient mice. Front Neurosci 12:613. https://doi. org/10.3389/fnins.2018.00613

60. López JF, Chalmers DT, Little KY, Watson SJ (1998) A.E. Bennett Research Award. Regulation of serotonin1A, glucocorticoid, and mineralocorticoid receptor in rat and human hippocampus: implications for the neurobiology of depression. Biol Psychiatry 43(8): $547-573$

61. Jovanovic H, Perski A, Berglund H, Savic I (2011) Chronic stress is linked to 5-HT(1A) receptor changes and functional disintegration of the limbic networks. Neuroimage. 55(3):1178-1188. https://doi. org/10.1016/j.neuroimage.2010.12.060

62. Richardson-Jones JW, Craige CP, Nguyen TH, Kung HF, Gardier AM, Dranovsky A, David DJ, Guiard BP et al (2011) Serotonin-1A autoreceptors are necessary and sufficient for the normal formation of circuits underlying innate anxiety. J Neurosci 31(16):6008-6018. https://doi.org/10.1523/JNEUROSCI.5836-10.2011

63. Joca SR, Padovan CM, Guimarães FS (2003) Activation of postsynaptic 5-HT(1A) receptors in the dorsal hippocampus prevents learned helplessness development. Brain Res 978(1-2):177-184

64. Carabelli B, Delattre AM, Pudell C, Mori MA, Suchecki D, Machado RB, Venancio DP, Piazzetta SR et al (2015) The antidepressant-like effect of fish oil: possible role of ventral hippocampal 5-HT1A post-synaptic receptor. Mol Neurobiol 52(1):206215. https://doi.org/10.1007/s12035-014-8849-8

65. Hellweg R, Zueger M, Fink K, Hörtnagl H, Gass P (2007) Olfactory bulbectomy in mice leads to increased BDNF levels and decreased serotonin turnover in depression-related brain areas. Neurobiol Dis 25(1):1-7

Publisher's Note Springer Nature remains neutral with regard to jurisdictional claims in published maps and institutional affiliations. 